ISSN 0258-7122

Bangladesh J. Agril. Res. 37(2): 295-299, June 2012

\title{
EFFECTS OF INSECTICIDES ON SUGARCANE TERMITES IN MODHUPUR TRACT
}

\author{
M. N. AlAm ${ }^{1}$, M. A. AlAm ${ }^{2}$, M. AbDUllah ${ }^{3}$ \\ M. BEGUM ${ }^{3}$ AND T. AHMED ${ }^{1}$
}

\begin{abstract}
An experiment was conducted with insecticides, namely Krisban 50WP, Neptune 48EC, Aincoban 48EC, Greater 48EC, Chlorguard 48EC, Chlorban 40.8EC, Vifos 20EC, Luciban 20EC, Bismark 20SP, Imidagold 20SL, Lorsban $15 \mathrm{G}$ to find out their effectiveness for controlling sugarcane termites and on the growth and yield of sugarcane at Sreepur. All these insecticides were applied @ 2.25/0.20 Kg ha ${ }^{-1}$ or 1 ha $^{-1}$ during plantation, April and May. All of them except Aincoban, Chlorgaurd and Bismark provided $71-97 \%$ termite population control. Germination of sugarcane bud was higher in chemical treated plot than the untreated control. Yield of cane increased in Greater 48EC, Chlorban 40.8EC, Luciban 20EC, Imidagold 20SL and Lorsban 15G treated plots.
\end{abstract}

Keywords: Saccharum officinarum, short residual, termite

\section{Introduction}

Among different insect pests termite is major pest of sugarcane. There are five species of termite identified as destructive to sugarcane in Bangladesh (Alam and Miah, 1997). As many as 13 species of termite are reported to cause damage to sugarcane in India. Termite infestation caused 30-60\% destruction of buds (Teotia et al., 1963 and Roonwal, 1981). Avasty (1967) reported it as 40\%, which results in yield loss of 33\%. Subterranean termites are the major problem attacking sugarcane crop from its germination through shoot emergence and finally it affects the quality of canes. At germination stage, the losses up to 90$100 \%$ have been recorded (Salihah et al., 1988). Koto et al. (2000) reported that termites live in the soil and damage sugarcane by excavating through the cane setts, leading to the death of buds and young shoots. Termite may attack any part of sett, but in the hard-rinded varieties, they prefer to attack the ends, eye buds and root bands (Choudhary et al., 1986 and Mill, 1992). The control of sugarcane termites was largely conducted with the application of insecticides in Pakistan (Sattar and Salihah, 2002; Ahmed et al., 2007). Organochlorin insecticides such as Heptachlor and Dieldrin have been used in the past but due to long residual effect these are harmful to beneficial insects and create serious problem to environment. The main purpose of this study was to find out the effectiveness of different insecticides against termite.

${ }^{1}$ Scientific Officer, Bangladesh Sugarcane Research Institute (BSRI), Ishurdi, Pabna, ${ }^{2}$ Ex. Director (Research), BSRI, Ishurdi, Pabna, ${ }^{3}$ Pricipal Scientific Officer, Entomology Division, BSRI, Ishurdi, Pabna, Bangladesh. 


\section{Materials and Method}

The experiment was conducted in a farmer's sugarcane field at Sreepur, Gazipur during 2006-07 cropping season following RCBD and replicated three times to identify the cheapest and effective insecticides against termite population. The variety Isd 36 was planted in $6 \mathrm{mx} 5 \mathrm{~m}$ plots. Two eyed setts were prepared and placed in trenches. Then tested insecticides Krisban 50WP, Neptune 48EC, Aincoban 48EC, Greater 48EC, Chlorguard 48EC, Chlorban 40.8EC, Vifos 20EC, Luciban 20EC, Bismark 20SP, Imidagold 20SL, Lorsban 15G were applied in trenches and setts were covered with soil. The insecticides like Krisban, Neptune, Aincoban, Greater, Chlorguard, Chlorban, Vifos, Luciban, Lorsban were applied @2.25 kg or litre/ha and Bismark and Imidagold were sprayed@0.20 kg or litre/ha. Data were collected on termite population two times, first in month of April 2007 at tillering stage when most of the setts are attacked and then in November 2007 at maturity stage. Also data on growth and yield parameter i.e., tillers, millable cane and yield of sugarcane were collected. Intercultural operations like weeding, earthing up, mulching, and irrigation were done as usual. To study the efficacy of applied insecticides data on termite population were taken twice. Five clumps per plot were uprooted with the help of spade. The uprooted setts/stools were placed on a thick polythene paper, then split with a knife and counted termite population. Statistical analysis was done and treatment means were compared with the control following LSD test. Percent efficacy of insecticides was also calculated by the following formula: $\%$ Efficacy $=\frac{P_{u}-p_{t}}{p_{t}} \times 100$ where, $\mathrm{P}_{\mathrm{u}}=$ population of termite in untreated and $\mathrm{P}_{\mathrm{t}}=$ population of termite in treated plots.

\section{Results and Discussion}

\section{Efficacy of insecticides on population control of termites}

In first population sampling on April, there were few termites in Lorsban, Chlorban, Luciban, Neptune, Vifos and Krisban treated plot recording 4.66-22.00 in number showing $84.82-96.78 \%$ efficacy (Table 1). The number of termites increased in other treatments of Aincoban, Greater, Imidagold, Chlorguard and Bismark where of controlling termites was much lower ranging from 29.88 to $57.93 \%$. The second sampling collected more termites, especially in Krisban Neptune and Bismark treatments. The insecticides lost their controlling capacity late after application. Greater, Chlorban, Vifos, Luciban, Imidagold and Lorsban effectively controlled termite population and resulted above 80 percent efficacy against termite population. Alam et al. (2001) also reported that the short residual chemicals Regent 3GR and Regent 50SC @ 100 g a.i. ha ${ }^{-1}$ significantly reduced sugarcane termites. 
EFFECTS OF INSECTICIDES ON SUGARCANE TERMITES

Table 1. Effects of different insecticides in reducing population of sugarcane termites.

\begin{tabular}{lcc|c|c}
\hline \multirow{2}{*}{ Treatments } & \multicolumn{2}{|c|}{15 April 2007} & \multicolumn{2}{c}{15 November 2007} \\
\cline { 2 - 5 } & Mean pop & Efficacy (\%) & Mean pop & Efficacy (\%) \\
\hline Krisban 50WP @ 2.25 kg/ha & 18.00 & 87.58 & 115.00 & 29.73 \\
Neptune 48 EC @ 2.25 L/ha & 11.33 & 92.33 & 100.00 & 38.89 \\
Aincoban 48 EC @ 2.25 L/ha & 78.66 & 45.75 & 55.00 & 66.39 \\
Greater 48 EC @ 2.25 L/ha & 41.66 & 71.26 & 2.66 & 98.37 \\
Chlorguard 48EC @2.25 L/ha & 61.00 & 57.93 & 21.33 & 86.96 \\
Chlorban 40.8EC@2.25 L/ha & 8.33 & 94.25 & 2.66 & 98.37 \\
Vifos 20 EC @ 2.25 L/ha & 22.00 & 84.82 & 3.33 & 97.96 \\
Luciban 20 EC@ 2.25 L/ha & 8.33 & 94.25 & 5.33 & 96.74 \\
Bismark 20 SP @ 0.20 kg/ha & 101.66 & 29.88 & 105.00 & 35.84 \\
Imidagold 20 SL @ 0.20 L/ha & 30.66 & 78.85 & 7.66 & 95.31 \\
Lorsban 15 G @ 2.25 kg/ha & 4.66 & 96.78 & 3.33 & 97.66 \\
Control & 145.00 & - & 163.66 & - \\
\hline LSD at 5\% & 15.50 & - & 15.98 & - \\
\hline
\end{tabular}

Table 2. Treatments of different insecticides on yield contributing characters and yield of sugarcane.

\begin{tabular}{lcccc}
\hline \multicolumn{1}{c}{ Treatments } & Tiller $\left(10^{3} \mathrm{ha}^{-1}\right)$ & MC $\left(10^{3} \mathrm{ha}^{-1}\right)$ & Yield (t/ha) \\
\hline Krisban 50WP @ 2.25 kg/ha & 174.00 & 89.66 & 83.39 \\
Neptune 48 EC @ 2.25 L/ha & 167.66 & 85.66 & 79.67 \\
Aincoban 48 EC @ 2.25 L/ha & 164.66 & 88.33 & 82.15 \\
Greater 48 EC @ 2.25 L/ha & 220.66 & 115.00 & 101.95 \\
Chlorguard 48EC @2.25 L/ha & 174.66 & 91.00 & 84.63 \\
Chlorban 40.8EC@2.25 L/ha & 178.33 & 97.00 & 86.87 \\
Vifos 20 EC @ 2.25 L/ha & 192.00 & 89.00 & 82.77 \\
Luciban 20 EC@ 2.25 L/ha & 197.33 & 101.66 & 96.55 \\
Bismark 20 SP @ 0.20 kg/ha & 191.00 & 92.66 & 86.18 \\
Imidagold 20 SL @ 0.20 L/ha & 225.66 & 118.33 & 110.05 \\
Lorsban 15 G @ 2.25 kg/ha & 223.33 & 96.33 & 89.59 \\
Control & 186.33 & 91.33 & 84.94 \\
\hline LSD at 5\% & - & - & 24.07 \\
\hline
\end{tabular}




\section{Effects of insecticides on sugarcane germination}

The early attack of termites to setts cause failure in germination and may cause as high as 33\% loss in yield (Ananthanarayana and David, 1986). The germination of sugarcane increased in all the insecticide treated plots (Fig. 1). The variation of germination occurred among the insecticide treatments. Krisban, Neptune, Greater, Vifos, Luciban, Bismark and Lorsban treatments had 6.11$13.42 \%$ more germination than control. The germination of setts by Chlorguard, Chlorban, Aimcoban and Imidagold treated plots was close to untreated sugarcane setts.

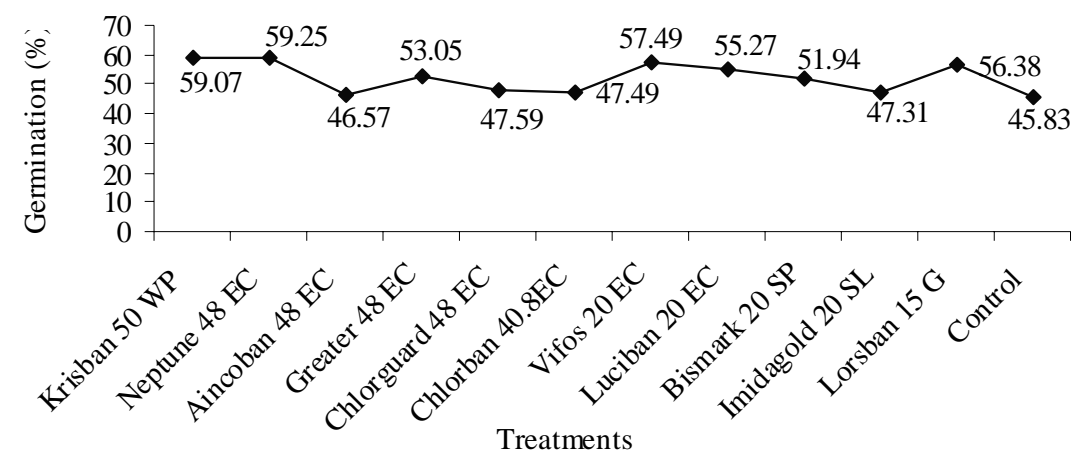

Fig. 1. Percentage of germination of sugarcane in different treatments

\section{Insecticides application on sugarcane plant character and yield}

Tiller production of treated sugarcane plot was not significantly different from that of control. Imidagold, Greater and Lorsban produced more tillers than other insecticides with greater millable cane (Table 2). The yield of sugarcane was also higher in these insecticide treatments. Alam et al. (2008) also reported that the highest cane yield was obtained in the short residual chemicals Baifos 20 EC treated plot and significantly differed with control. The yields in other insecticides treated plots were not significantly different from untreated control.

The overall results indicated that termite population might be controlled effectively with treatment of some of the insecticides from planting setts to the harvest of sugarcane. The granular formulation of insecticides was more effective against termites and germination of sugarcane.

\section{References}

Ahmed, S. M. A., Riaz and A. Hussain. 2007. Assessment of the damaged and population of termites (Odontotermes and Unicolor) under various methods of insecticide application. Int. J. Agri. Biol. 9: 125-28. 
Alam, M. A. and M. A. H. Miah. 1997. Akher Anistakari pokamaker (in Bangla). In: Bangladesher Krisher Anistakari Pokamakor. Vol. 2. T. U. Ahmed and A. F. M. A. Jalil (eds). Bangla Academy, Dhaka, Bangladesh, pp.1-49.

Alam, M. A., M. M. Biswas, M. Abdullah and M. A. Rashid. 2001. Efficacy of Fipronil in Controlling Sugarcane Termites. Bangladesh J. Sugarcane 23:15-18.

Alam, M. N., Sohel, M. A. T., Akhtar, S., Islam, N. and Begum, F. 2008. Evaluation of different short residual insecticides in controlling sugarcane termites. Bangladesh $J$. Crop Sci. 19 (1): 63-66.

Ananthanarayana, K. and David, H.1986. Termites. In: Sugarcane Entomology in India, David, H.; easwaramoorth, S. and Yayanthi, R. (Eds.). Sugarcane Breeding Institute, Coimbatore, Tamil Nadu, India. Pp. 207-231.

Avasthy, P. N. 1967. Sugarcane pests in India. PANS (A), 13: 111-117.

Chaudhary, J.P., S.P. Singh, K.K. Mrig and S.C. Bhardwaj. 1986. Evaluation of different control schedule for the suppression of major insect pests on sugarcane pests. Pestic. Sci. 9: 445-457.

Koto, I.N., K.I. Nwasu and L.D. Busari. 2000. Control of termites in sugarcane using insecticides. Sugar Tech. 2(4): 17-20.

Mill, A.E. 1992. Termites as Agricultural Pests in Amazoma, Brazil. Outlook and Agriculture 21(1): 41-46.

Roonwal, M.L. 1981. Termites of agricultural importance in India and their control. In “ progress in soil biology and Ecology in India”.(Vereesh, G.K.ed.). Tech. Ser. 37. Univ. Agric, Sci., Bangalore. P 253-256.

Salihah, Z., M. Shah and A. Sattar.1988. Survey of sugarcane termites of Nowshehra and Charsadda Tehsils. In: Proceedings of $8^{\text {th }}$ Pakistan Congr. Zool., 8: 289-97.

Sattar A. and Z. Salihah. 2002. Delineation of foraging terrtitories of Heterotermes indicola (Isoptera: Rhinotermitidae) by using a dye, Nile Blue A. In: Proceedings of Pakistan Congr. Zool. 22:10.

Teotia, T.P.C., K.M. Gupta, V.G. Rajani and Gangasagar. 1963. Effective control of termites and shoot borers through soil application of heptachlor in sugarcane crop. Indian J. Sug. Cane Res. Div. 7: 203-211. 